\title{
TRAZOS Y PINCELADAS: LA CONDENSACIÓN LITERARIA COMO PRINCIPIO DE CONSTRUCCIÓN EN "AMBYSTOMA TRIGRINUM" DE SALVADOR ELIZONDO
}

\author{
Berenice Romano Hurtado \\ Universidad Autónoma del Estado de México \\ brhurtado@gmail.com
}

\begin{abstract}
RESUMEN: En este artículo se trabaja un cuento del escritor mexicano Salvador Elizondo para subrayar la importancia de la elipsis y la condensación literarias como recursos fundamentales de su escritura. Como una forma de subrayar los temas de la transformación y la reiteración en sus textos, se hace una analogía con algunas obras del artista plástico M. C. Escher.
\end{abstract}

PALABRAS CLAVE: brevedad, narrativa, transformación, escritura, pintura

\begin{abstract}
This paper analyzes a short story by the Mexican author Salvador Elizondo in order to highlight the significance of ellipsis and literary condensation as key resources of his writing. As a way of highlighting the themes of transformation and iteration in his works, I establish an analogy with the work by visual artist M. C. Escher.
\end{abstract}

KEYWORDS: brevity, narrative, transformation, writing, painting

Como no puedo pintar porque no tengo materiales me pondré a escribir. SALVADOR ELIZONDO, Diarios

En 1952, Salvador Elizondo llegó a París con la intención de formarse como pintor. Con estudios de pintura en la escuela "La Esmeralda" y en la Academia de San Carlos, Elizondo se aventuró a Europa con la idea clara de dedicarse a las artes plásticas. A pesar de que combina este interés con el cine y con la escritura, cree que su perfil artístico corresponde al de la pintura. En sus Diarios escribe durante un largo periodo acerca de las exploraciones que lleva a cabo en esta materia. El 29 de septiembre de 1956, por ejemplo, anota: "Me consuelo pensando que Joyce tardó 14 años en escribir Ulises y yo no soy novelista y, si algún día la termino [su novela], no podré publicarla" (2015: 60). Es decir, Elizondo estaba convencido de su vocación de pintor y no veía la escritura como una posibilidad real.

Sin embargo, fue en la escritura donde pudo desarrollar y mostrar su talento, lo que le otorgó una posición privilegiada dentro del mundo cultural mexicano de los años sesenta. La experiencia que por varios años vivió con la pintura, no obstante, le permitió un acercamiento a las artes visuales que ya antes había vivido con el cine. Hijo de un productor cinematográfico, Elizondo se vio interesado desde muy joven en diversas manifestaciones 
artísticas vinculadas con lo visual. De ahí que no sea extraño encontrar en su obra literaria una serie de recurrencias y procedimientos que recuerdan los empleados en la pintura o en el cine y que fundan la poética elizondeana.

En este artículo me interesa subrayar algunos de estos en el cuento "Ambystoma trigrinum", para vincularlo con ciertas imágenes y recurrencias temáticas del artista plástico M. C. Escher. Pretendo mostrar cómo en la escritura de Elizondo hay una preocupación por la imagen y sus transformaciones, por los textos ideográficos y por las imágenes geométricas; motivos que encuentran una relación análoga con el arte visual de Escher. Particularmente quiero acentuar que todo esto supone una poética en Elizondo, que desemboca en el recurso de la condensación narrativa como medular en sus textos breves.

El grafógrafo es un libro de relatos que se publicó en 1972, cuando Salvador Elizondo ya había ganado el Premio Xavier Villaurrutia con Farabeuf. En este compendio de textos, Elizondo trabaja alrededor de una idea central que atraviesa su obra: la escritura como artificio. Entre los diversos relatos que elabora para desarrollar esta inquietud, está el que da nombre al libro y que pone de manifiesto la imagen prismática que representa para él el acto de escribir:

Escribo. Escribo que escribo. Mentalmente me veo escribir que escribo y también puedo verme ver que escribo. Me recuerdo escribiendo ya y también viéndome que escribía. Y me veo recordando que me veo escribir y me recuerdo viéndome recordar que escribía y escribo viéndome escribir que recuerdo haberme visto escribir que me veía escribir que recordaba haberme visto escribir que escribía y que escribía que escribo que escribía. También puedo imaginarme escribiendo que ya había escrito que me imaginaría escribiendo que ya había escrito que me imaginaría escribiendo que había escrito que me imaginaba escribiendo que me veo escribir que escribo. ${ }^{1}(9)$

El texto presenta a un narrador que cuenta que escribe. Esa es la acción central, la de escribir, y paralelamente están las de recordar, mirar e imaginar, cada una en vinculación con un tiempo: el pasado, el presente y el futuro, respectivamente. En el texto, que funciona como una especie de epígrafe para el libro - ya que suma las recurrencias temáticas y estructurales que lo conforman-, se integran imágenes superpuestas que dan distintas perspectivas de una misma acción. Este conglomerado de representaciones pretende dar, en una sola imagen, el cúmulo de momentos que potencialmente la componen. Es decir, Elizondo, a partir de la concepción del ideograma chino, configura un texto que en un mismo espacio de lectura difracta sus diversas versiones, y en el que se tiene una

[f]ocalidad, entonces, de lo visual; capacidad de la imagen por contener (por dar cuenta) del mundo, y, subsidiariamente, y como corolario, quizá [...] un pensamiento imaginativo, mucho más adelantado que un pensamiento conceptual, desequilibrándose a favor de lo primero el viejo orden histórico, en el cual se compensaba por un lado el poder de la concepción y, por otro, el de la representación. (de la Flor, 2007: 66)

De ahí que la imagen que proyecta el autor en la mente del lector sea la de un prisma: un cuerpo geométrico que en cada una de sus caras da una interpretación distinta: en un solo trazo concepción y representación. De entrada al libro se tiene, entonces, un escrito que habla sobre la escritura misma como un juego de yuxtaposiciones, organizado en un solo trazo, para

\footnotetext{
${ }^{1}$ En adelante se citarán los cuentos de la edición del Fondo de Cultura Económica, México, 2013. Se pondrá el número de página frente a cada cita.
}

Berenice Romano Hurtado: "Trazos y pinceladas: la condensación literaria como principio de construcción en «Ambystoma trigrinum» de Salvador Elizondo" 
hablar del artificio escritural, la posibilidad de la caligrafía como imagen y la fuerza del texto breve.

“Ambystoma trigrinum" forma parte de El grafógrafo. Es un relato que se construye bajo la apariencia de un texto científico para hablar de la escritura: se trata, en términos generales, de la exploración que hace un escritor sobre la anatomía y características del ajolote. Tras la exposición de los rasgos del animal, el narrador crea por analogía un universo en el que describe el trabajo de la escritura y sus transformaciones.

El relato está dedicado al escritor cubano Severo Sarduy, quien en el mismo año en que se edita El grafógrafo publica Cobra, un texto en el cual, igual que en los de Elizondo, se crea una escritura que rompe con el canon que el Boom latinoamericano había cimentado. Como texto eminentemente del Posboom, "en Cobra, la escritura se presenta como el arte de la elipsis, el arte de la digresión, el arte de recrear la realidad, el arte de restituir la historia, el arte de descomponer un orden y componer un desorden, y, finalmente, como el arte del remiendo" (Herrera, 2006: 139). Tal como sucede en la escritura de Elizondo.

El guiño que hace Elizondo con la dedicatoria a Sarduy en "Ambystoma trigrinum", da cuenta de sus propios intereses y de una forma de escritura que se desarrolla con preocupaciones afines a las del cubano. Los puntos de convergencia entre ambos escritores quedan muy bien ilustrados en el cuento de Elizondo, pero asimismo en el comienzo de $\mathrm{La}$ simulación de Sarduy:

La Simulación conecta, agrupándolos en una misma energía — la pulsión de simulaciónfenómenos disímiles, procedentes de espacios heterogéneos y aparentemente inconexos que van desde lo orgánico hasta lo imaginario, de lo biológico a lo barroco: mimetismo (¿defensivo?) animal, tatuaje, travestismo (¿sexual?) humano, maquillaje, mimikry dress art, anamorfis, trompe-l'oeil. El espacio donde se expande esa galaxia es el de la Pintura: reflexión y homenaje. (1982: 8)

En esta línea, la escritura responde a ese principio de simulación cuando puede ser tanto el discurso que implica, como el animal que con él es representado. Según Sarduy, la simulación radica sustancialmente en vincular en una misma energía - trazo plástico o imagen discursiva - dos elementos en apariencia disociados — desde lo orgánico hasta lo imaginario - que encuentran su lugar en la analogía, en la cual, una vez más, se afirma que "la mutación de un individuo a otra especie es posible en función de la existencia de un sistema polar" (21), que a su vez puede representarse con la Cinta de Moebius II de Escher, en la que, de nuevo, se conjugan dos universos hechos uno —el natural y el artificial—, en la continuidad infinita de la estructura sobre la que transita lo orgánico. Castillo indica que "[1]as palabras originadas y acuñadas en el deslizamiento metaforizado a través de la cinta de Möbius, son el suceso que no tiene otro lugar que el texto y ningún otro instante que el preciso momento de la escritura y de la lectura que cita, recita y concita nuevas grafías y lecturas" (2006: 69). 


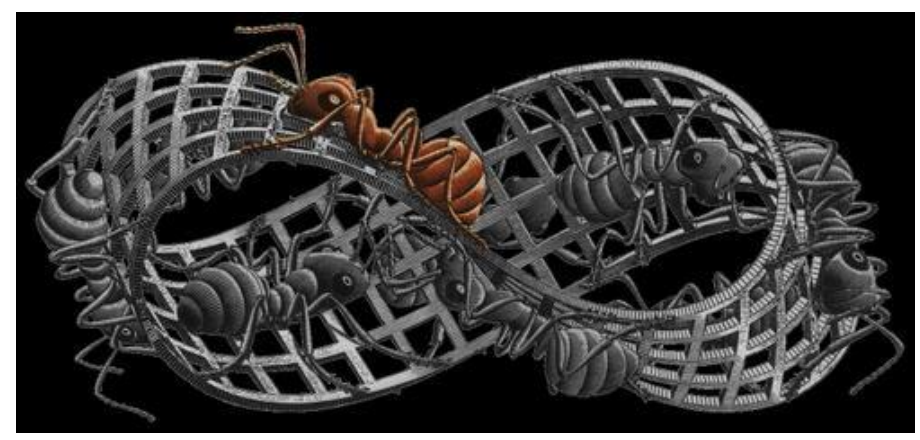

Cinta de Moebius II

M. C. ESCHER

En su contacto con el cine, Elizondo se interesó en la teoría sobre el montaje de Sergéi Eisenstein, en la cual el cineasta, sobre la base de algunos planteamientos teóricos formalistas, desarrolla la idea de yuxtaponer distintos planos del lenguaje fílmico para crear una tensión y efectos emotivos. ${ }^{2}$ Los distintos montajes que propone (métrico, rítmico, tonal, armónico e intelectual), pretenden cargar en una imagen los diversos planos narrativos y de construcción que la harán más compleja y significativa. En esta línea, así como Eisenstein se vale de presupuestos pensados originalmente para la poesía, Elizondo encuentra sumamente estimulante el proceso creativo del realizador para trasladarlo a la escritura.

Los términos de corte e injerto que se propusieron como método de escritura entre los teóricos de la posmodernidad durante la década de los sesenta (Deleuze, Derrida), se relacionan de cierta forma con el montaje de Eisenstein y con la escritura de Elizondo, quien ensambla distintos registros (literatura, cine y pintura, por ejemplo) para crear un discurso pletórico de sentido. Igual que lo hace Sarduy en su escritura.

En "Ambystoma trigrinum" se enhebran el discurso científico y el literario en la alusión al ajolote, el axólotl —monstruo de agua en náhuatl-, como un ser de transformaciones. El reiterado interés del escritor por las artes visuales, y la mención de ciertas imágenes y recursos de repetición, ha llevado a relacionar su propuesta literaria con litografías de Escher en las que a su vez representa salamandras o algún otro anfibio. La vinculación, desde luego, no se detiene en el motivo del relato, por un lado, y el de la litografía, por otro, sino que se extiende hasta los niveles más profundos de uno y otra donde se puede decir que los temas en Elizondo se vuelven plásticos y sus preocupaciones narrativas se ilustran en las visuales de Escher.

En “1971, el escritor Salvador Elizondo compra ejemplares [de ajolote] en Xochimilco para estudiarlos y hacer experimentos de mutación asesorado por el doctor León de Garibay lo que lo motiva a escribir el cuento" (Lavista, 2009: 65) "Ambystoma trigrinum". En el íncipit del cuento, el escritor transcribe la definición que la Real Academia da del ajolote, específicamente, la acepción zoológica, lo que marca desde el comienzo el tono científico que atraviesa todo el escrito. A la manera de una bitácora de laboratorio, un escritor — que figura como el personaje-narrador en el texto-, describe los experimentos que realiza sobre el ajolote y las distintas reflexiones que esto le produce respecto de su propio quehacer. Lo que se revela desde el comienzo es la fascinación del observador - este estudioso que es un

\footnotetext{
${ }^{2}$ Escribe el 6 de julio de 1954: "Estoy haciendo un libro de notas referente a las posibilidades de utilizar el principio de montaje en todas las artes.” Diarios. 1945-1985. Fondo de Cultura Económica, México, 2015.
} 
científico y un escritor a la vez - por la posibilidad de transformación latente en el ajolote, el cual permanece como larva toda su vida, pero contiene en su naturaleza la capacidad de metamorfosearse en salamandra, si se encuentra en las condiciones idóneas para ello.

Esta aptitud del ajolote, que ha sido tema en otras narraciones, ${ }^{3}$ también ha despertado el interés de artistas plásticos. Paulina Lavista, en relación con el cuento de Elizondo, escribió:

Los artistas plásticos no escapan a explorar al "axólotl" como una posibilidad de tema para su expresión personal y en 1978 el hoy extinto Foro de Arte Contemporáneo, en su apoteótica exposición inaugural, presentó en peceras ejemplares vivos de la variedad mexicana junto con el trabajo multidisciplinario de dos pintores [...], un dibujante [...] y un fotógrafo en torno a los ajolotes. (2009: 65)

En este sentido, M.C. Escher tiene distintas elaboraciones plásticas en las que destaca no solo salamandras, anfibios o reptiles, sino la transformación que los vincula entre sí. El tema en muchas de sus litografías es el del cambio y las posibilidades de metamorfosis de diversos objetos y seres. En su trabajo es frecuente encontrar la preocupación por formas que dan una ilusión de movimiento, por medio de la teselación del plano, ${ }^{4}$ al llevar imágenes de un estado a otro con dibujos que se repiten en mosaico para mostrar en una misma figura el punto de enlace entre dos momentos y su transformación. Estas son las inclinaciones que sobresalen en la obra de Escher y que de alguna forma han llevado a algunos críticos a vincularlo con el trabajo de Elizondo. ${ }^{5}$

En "Ambystoma trigrinum" se exploran "modelos discursivos plurales en el texto literario y la reflexión sobre la escritura. A partir de la condición larvaria del ajolote y su potencia de metamorfosis, Elizondo establece una relación entre el animal y la forma textual. Bajo este principio analógico, el texto se muestra como reflejo del objeto de su escritura" (Gutiérrez Piña, 2014: 298). La relación entre el ajolote y la escritura, y entre esta y la pintura de Escher, se sujeta en el mismo punto: la autorrepresentación.

En el cuento, "el cultivo de ajolotes se realiza en la casa de un escritor con el fin de hacer observable un hecho relativo a la evolución de la especie. Esa observación de la mutación de un individuo a otra especie es posible en función de la existencia de un sistema polar de órganos que según sean estimulados o inhibidos provocan o impiden el desarrollo" (21). Los datos científicos y toda la observación que se hace en torno al animal que se está estudiando, provienen del escritor, quien, de igual forma que el ajolote, se bifurca en un científico, por un lado, y en un creador de historias, por otro. Lo mismo sucede con el tono del discurso, que va de un carácter científico con el que se dan las características del animal, a uno literario, en el cual, a partir del símbolo del ajolote, se empieza a refigurar otra realidad: Axolotitlán, "una ciudad fundada para su población por seres genéticamente transmutantes" (24). Esta ciudad poblada por criaturas "ambiguas" supone espacialmente una posibilidad doble, y pone en el centro uno de los intereses temáticos de Elizondo: lo especular. El escritor

\footnotetext{
${ }^{3}$ Julio Cortázar, “Axolotl”, 1952; Juan José Arreola, "El ajolote”, 1959; Octavio Paz, "Salamandra”, 1962; José Emilio Pacheco, "El reposo del fuego", 1966.

${ }^{4}$ Es un término que proviene de la geometría y que hace referencia a una regularidad o patrón de figuras.

${ }^{5}$ En este sentido se puede mencionar el estudio "En el mundo del Hipogeo secreto de Salvador Elizondo", de María Esther Castillo García, Anclajes, X/10 (diciembre de 2006), 61-71. Así como "Las posibilidades de la escritura en La historia según Pao Cheng”, de Claudia Macías Rodríguez y Kim Dong-Hwan, Espéculo. Revista de estudios literarios, Universidad Complutense de Madrid, 2004.
} 
dual, así como el ajolote también doble, reflejan a su vez espacios que se multiplican. El ajolote vive en el agua y remite a un mundo acuático, mientras que la salamandra sale a un espacio terrestre. Este reflejo de dos universos se ve representado en "Tres mundos" de Escher, donde el artista revela una realidad especular en la que no se puede discernir dónde termina la tierra y comienza lo acuático. Las ramas de los árboles que suponemos están a la orilla del agua, en el reflejo - en la imagen invertida como en un espejo- lucen igual que raíces, es decir, se representa lo terrestre como enraizado en lo acuático, mientras que el agua sujeta y se colma de hojas, como un árbol. El enorme pez en el centro representa el engarce entre estos dos espacios, es la parte orgánica que simboliza el origen de la vida, que comienza en el agua, pero que contiene la posibilidad de expandirse fuera de ella.

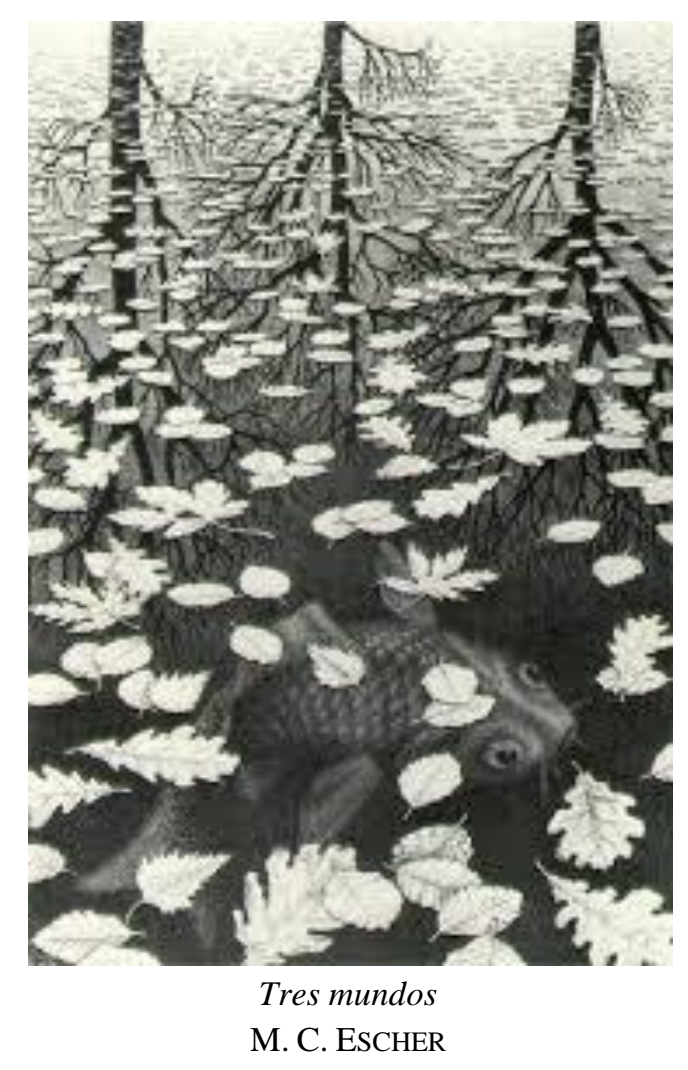

Igual que el ajolote, que en su naturaleza carga la posibilidad latente de ser otro y de habitar distintos espacios. Los diversos reflejos en la obra de Escher funcionan entre sí como imágenes especulares que multiplican la presencia de cada elemento dentro del cuadro. En Elizondo, esta reproducción especular se da desde la eventual mutación del ajolote, hasta las facultades de transformación de la escritura, y de ahí a la analogía entre esta escritura y la obra de Escher. Dice Elizondo en "Tractatus rethorico-pictoricus" que "entre el espejo y la mirada medra el mundo de lo otro" (69).

“Tractatus rethorico-pictoricus" es otro cuento de El grafógrafo, en el que el escritor trata de explicar la pintura en analogía con la escritura. Enuncia como uno de los preceptos "[f]ormas básicas esenciales de la idea de la «representación»: la escritura (exposición de la idea en el tiempo) la pintura (disposición de la idea en el espacio)" (65). Con lo que pone en un mismo plano, el de la representación, a las dos materias. La vinculación con Escher se puede mantener a lo largo del cuento de Elizondo porque la analogía de la escritura con el 
ajolote lo atraviesa. Lo mismo que la imagen de las metamorfosis de reptiles ocupa un lugar importante en la obra de Escher.

Como antes mencioné, el término de montaje de Eisenstein es un principio que rige la escritura de Elizondo y que de alguna forma se encuentra también en el trabajo de Escher. La fascinación de Elizondo por los ideogramas chinos radica en parte en que tienen una mayor carga semántica en un solo trazo. Visualmente implican la representación de una idea completa en una sola imagen. En este punto descansa parte de la poética elizondeana: en crear una escritura que en poco espacio comprenda un discurso completo. Esta búsqueda desemboca en textos muy breves, pero además en un estilo que condensa en una imagen todo un concepto, como si la inscripción ya no fuera tal, sino la reproducción visual de lo que se escribe, y esta, a su vez, la escritura misma. En "La autocrítica literaria", Salvador Elizondo dice al respecto:

¿cómo podría ese escritor que se llama Yo crear una obra sin que para ello empleara o aplicara, al acto mismo de crear esa obra, una potencia que no fuera, ella misma, acentuadamente crítica?, ¿cómo podría ese Yo crear una obra que no estuviera hecha de la sustancia de sí misma que el concebirla crea?, ¿de qué podría estar hecha la obra si no de sí misma y de la conciencia de sí misma en su creador? (2013b: 198)

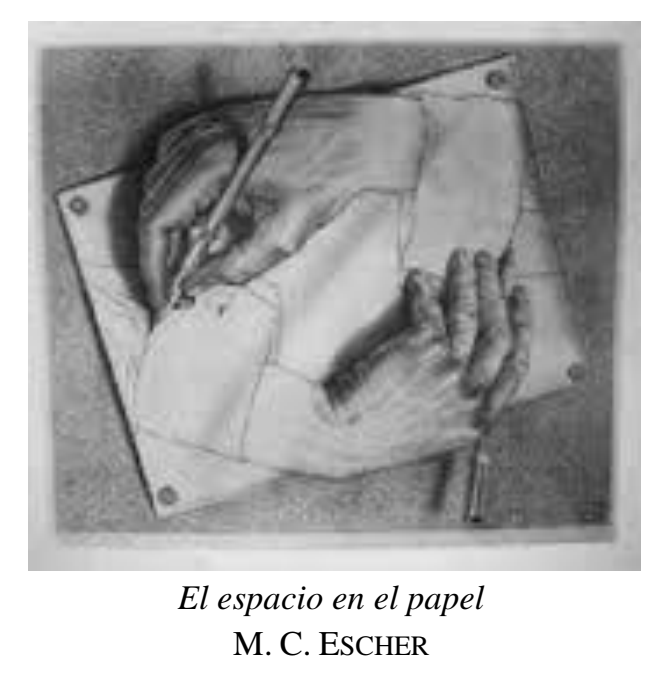

Una vez más subyace en esta declaración no solo la autorreferencialidad de la literatura, sino el fundamento especular que así mismo reproduce Escher. No solo en la litografía de $E l$ espacio en el papel, sino en diversas obras en las cuales la especularidad es uno de los principios que se representa en ellas. La obra hecha de sí misma es el movimiento en espiral de una recursividad narrativa que recae en la escritura como discurso elíptico, es decir, uno que vuelve sobre sí mismo; y en la pintura, en imágenes que significan en el engarce con otras, y que juntas dan la ilusión de continuidad infinita.

La escritura está hecha de sí misma, dice Elizondo; en su intención de exhibir y repensar la función de la escritura, subyace el deseo de mostrar una refiguración en el uso del lenguaje. Para este autor, el trabajo de escritura radica en poder producir la mayor cantidad de sentido en poco espacio; por ello, sus temas aluden a este lenguaje por el lenguaje mismo, en el que lo más importante no es lo que se dice, sino el proceder de la escritura. En "Ambystoma trigrinum" el narrador llama al ajolote "una figura connubial [que] es también 
un grafema fálico vivo" (21); la analogía del ajolote con la escritura — “el cultivo de ajolotes se realiza en la casa de un escritor" (21) - señala de nuevo la intención de definirla, a ella también, como un proceso de transformación continuo. El sistema polar con el que explica al ajolote es el mismo que puede definir al lenguaje literario: uno con planos cruzados, sintagmáticos y paradigmáticos, que suman las distintas y múltiples combinaciones de sentido. De ahí que la narración de Elizondo derive en la fantasía de una ciudad que contiene a los ajolotes, en la que "todos sus monumentos se yerguen en honor de la fuerza que el centro de la tierra ejerce sobre la escritura" (25), es decir, una fuerza que determina todas las representaciones, porque el cambio continuo, la posibilidad de transformarse, habla de no ser nunca uno mismo, sino la representación, siempre mutante, de algo más.

En su narración, Elizondo reflexiona sobre la escritura por medio de la imagen y la capacidad de transformarse del ajolote. En este sentido, el relato mismo es la escritura y su objeto de estudio. El texto cambia continuamente y da saltos que parecen no solo de tono discursivo - de lo científico a lo subjetivo-, sino espacial, cuando parece que en momentos está explorando al ajolote en una especie de "laboratorio escritural", y en otros ese "experimento" sobre las transformaciones lo lleva a imaginar la ciudad mítica de Axolotitlán, que desde luego alude a Tenochtitlán.

La analogía que hace Elizondo entre la escritura y el ajolote no solo recae sobre la posibilidad latente de este de transformarse en algo más, sino en el hecho de que la observación cuidadosa que realiza el escritor en el laboratorio lo hace ver como un trazo significante. En este sentido, la relación que encuentra el autor tiene que ver con una imagen fálica — el grafema fálico —, que no solo le remite a la imagen de un pene, sino a elevaciones erectas sobre las que, dice el narrador, se sostiene Axolotitlán. Es decir, el elemento fálico, diseminador de escritura, supone también una fuerza en el orden discursivo. El ajolote puede mutar o permanecer toda su vida en estado larvario, y para el escritor esto se traduce en un trazo — un pensamiento - que puede no transformarse o que puede, en el signo fálico, regar su semilla y multiplicar el sentido. Es por ello que el narrador va trasladando su discurso de uno científico, en el que trata de ser objetivo y señalar rasgos del ajolote como si fuera algo más, hasta llegar a otro meramente ficcional en el que el animal es eso otro que el escritor ha deseado que fuera.

En “Ambystoma trigrinum" se lee: “en la digresión no está la esencia, sino la vida de la prosa" (27), porque la desviación en la escritura elizondeana supone vertientes nuevas de significado que a su vez se difractan en otras infinitamente. De ahí que la imagen fractal me parezca idónea para explicar este universo de escritura ramificada en espejo, diseminada a partir del signo fálico que representa el ajolote. Dice el narrador:

Digresión sobre la escritura. Un proyecto crítico interesante: totalmente conseguir sustraer, por medio de algún proceso analítico especial, el principio en el que se fundan las antiguas arquitecturas de su contexto y obtener de ello las leyes de esa geometría rígida, de esa música tan escalonada, de esa posibilidad de espacios tan especiales; de aberturas y clausuras tan desconcertantes e inmensas. Obtener de ello la sabiduría fundamental de esas construcciones que se yerguen en el sentido de la gravedad y no en contra de ella. Aquí no hay columnas; solamente cimientos. (27-28)

En la concepción de Elizondo, el espacio tiene un papel particular. Esta mirada sobre el detalle como unidad narrativa, que caracteriza la perspectiva elizondeana, hace que con 
frecuencia se consideren como espacios estructuras que no suelen entenderse así. La escritura misma es una suerte de lugar, parte de esta arquitectura a la que alude la cita, organizado como una geometría compleja que tanto abre como cierra - umbral posmoderno- los significados. Una geometría tal es la que sostiene la organización fractal en la literatura: "aquella que multiplica los signos lingüísticos, dentro de un orden sintáctico, como si se tratase de un juego de espejos que busca en esa repetición, en ese juego, una dinámica dentro de lo infinito, de lo laberíntico o de lo circular" (Paniagua, 2008: 25). Y esa forma que se organiza en la iteración se mueve hacia dentro de sí misma en una narrativa breve, en Elizondo, y en planos isométricos en Escher. Porque en los trazos que suman sentidos, como hace Elizondo, es que se puede edificar sobre cimientos; es decir, no en línea recta hacia arriba (la acumulación de significado), sino sobre el mismo espacio, en la recursividad narrativa o en modelos periódicos en pintura. Ambas organizaciones geométricas muestran la transmutación de las formas.

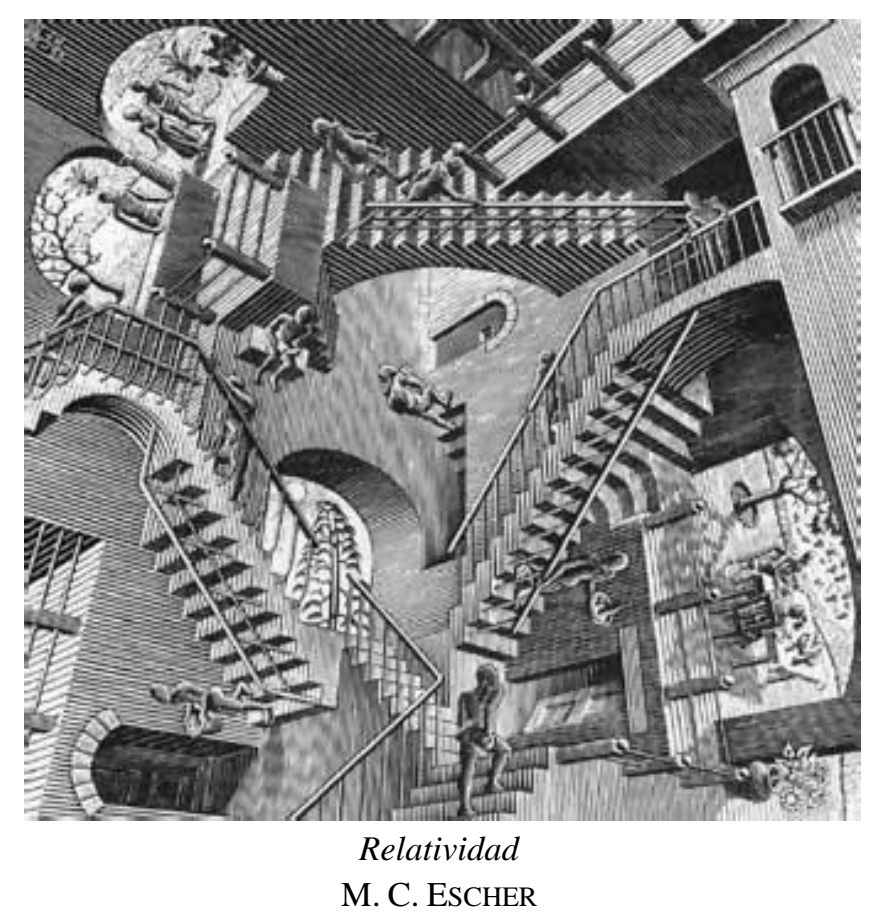

En "Ambystoma trigrinum", la salamandra y el ajolote se representan como seres liminales: aquella como frontera de otros universos; el ajolote como el espacio en el que suceden los cambios. Las "mutaciones biológicas" que se narran en el texto son también transformaciones geométricas - fractales - que no se decantan por una u otra forma, sino que guardan las propiedades de todas las líneas fronterizas para potenciar las combinaciones y los significados. El mago, alquimista, manipulador de células, biólogo del lenguaje que es el escritor de la narración, cultiva los seres "genéticamente transmutantes" (25), es decir, seres ambiguos, como la escritura.

En la narración "Tractatus rethorico-pictoricus", a la que antes aludí, se redacta un tratado de pintura en el que se expone una concepción peculiar de la inscripción: se habla sobre la pintura, pero en relación con una escritura que se transforma en pensamiento, en imagen significante. En este sentido, el texto breve se entiende como una sola idea abierta a 
múltiples caminos de significado: representada exponencialmente al concebirse como pensamiento.

En la narración se describe la "Operación pictórica", que tiene una parte dedicada al ojo, que corresponde al genio; otra a la mano, dirigida a la destreza o técnica; y finalmente la que se refiere a la luz, que pertenece a la poética: el "tratado imposible" (59). Igual que en un espacio geométrico fractal, aquí se vincula la poética con lo visual porque supone la técnica, el proceder, de una escritura hecha de imágenes. Y estas imágenes, igual que en la realidad fuera del texto, surgen por medio de la luz; en este caso, la luz no se interpreta simplemente como el recurso para ver o iluminar, sino como la energía que atraviesa el cuerpo traslúcido y fractal que es esta poética y que se difracta en una infinidad de imágenes: la luz reverbera y manifiesta el carácter diverso del lenguaje. Con ello queda sentado que la única forma concreta y real del pensamiento es la escritura; es la prueba de que hay un pensamiento, o de que lo hubo; la única expresión que demuestra que se es. La escritura les da cuerpo y peso a las ideas, pero camina como ellas, en ramificaciones que no reconocen un orden: "Si no fuera por la escritura yo podría pensar que el pensamiento mismo que concibe la realidad del mundo como una ilusión y como una mentira es, él mismo, una ilusión, una mentira" (64). Igual que antes, la narración alude a la brevedad en la aglomeración de sentido de la escritura, que carga más significado en pocas palabras: cuando se dice "vaso" o se dice "alma", "ninguno de los dos tiene nada que ver con el que condensadamente trazamos con la punta de la pluma cuando escribimos alma, vaso" (66).

Los textos breves de El grafógrafo, aunque independientes entre sí, representan cada uno un trazo del signo gráfico que es el libro completo. Las narraciones se van engarzando casi de forma imperceptible para conformar una idea que se repite continuamente de manera transversal por toda la obra: la recursividad del texto breve y sus posibilidades temporales y espaciales. Por otro lado, de Escher se puede decir que "la dualidad, los desdoblamientos y la repetición son motivos constantes en la producción del artista holandés" (Martínez, 2010: 214). De la misma forma que todos estos son temas y recursos en Elizondo. Para ambos el lector/espectador es un participante dinámico, fundamental en la refiguración de mundos imposibles y del juego de las percepciones.

Las imágenes y escritura autorreflexivas son un recurso para condensar una gran cantidad de sentido en poco espacio. Para Elizondo, se trata de la búsqueda de un lenguaje absoluto que sea capaz de "describir la experiencia subjetiva del hombre en tanto «cuerposujeto-de-la-percepción»" (Gutiérrez, 2014: 312, n. 21). En este sentido, la escritura pura que busca el autor sería esta en la que el propio lector, igual que el discurso de Elizondo y las litografías de Escher, se integra al juego de las transformaciones para también él, continuamente, mutar en cada lectura. 


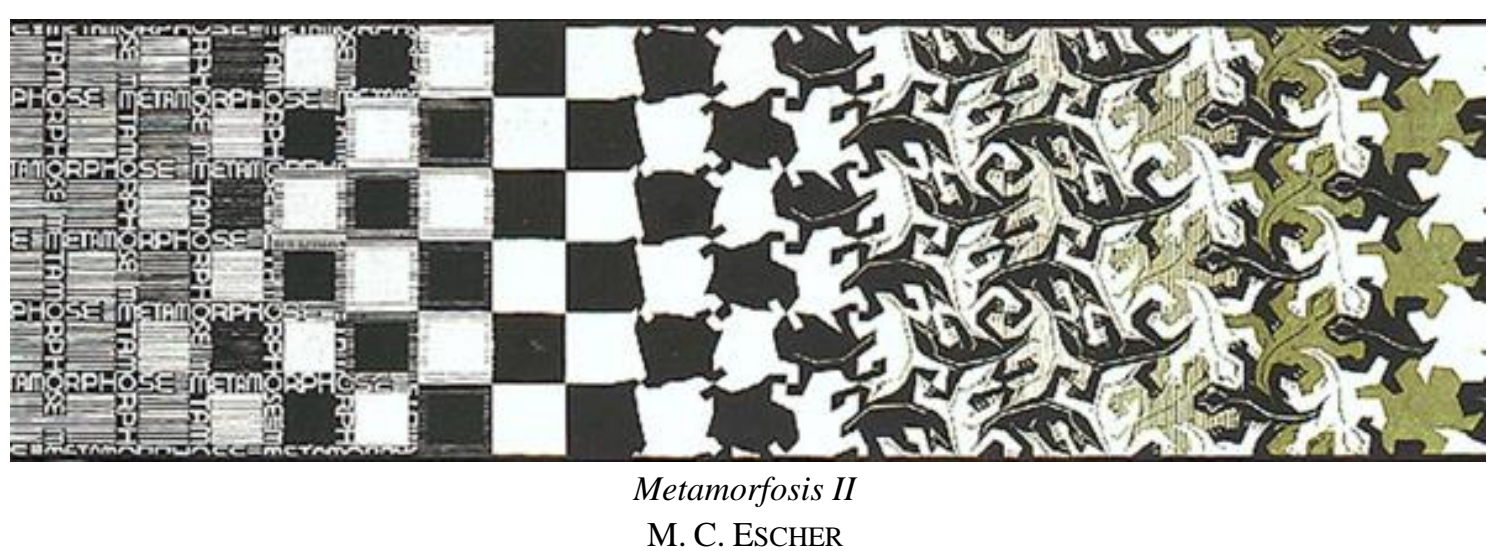

\section{Bibliografía}

CASTILlO GARCÍA, María Esther: "En el mundo del Hipogeo secreto de Salvador Elizondo", Anclajes X/10 (2006), 61-71.

DE LA FLOR, Fernando R.: "El impacto de los Visual Studies y la reordenación del campo de disciplinas del texto en nuestro tiempo", Hispanic Issues Online 2 (2007), https://cla.umn.edu/sites/cla.umn.edu/files/hiol_02_05_delaflor_el_impacto_de_los_visual_st udies.pdf, 18/09/2016.

ELIZONDO, Salvador (2013a): El grafógrafo. Fondo de Cultura Económica, México.

ELIZONDO, Salvador (2013b): Teoría del infierno. Fondo de Cultura Económica, México.

ELIZONDO, Salvador (2015): Diarios. 1945-1985. Fondo de Cultura Económica, México.

GUTIÉRREZ PIÑA, Claudia (2014): “«Ambystoma trigrinum» de Salvador Elizondo: escritura en metamorfosis". En Carmen ÁLVAREZ LOBATO (coord.): Monstruos y grotescos. UAEM, Aldus, México, 297-316.

HERRERA, Lizardo M.: “Cobra y el juego de la simulación”, Kipus. Revista andina de letras, 20 (2006), 139-154.

LAVISTA, Paulina: “A propósito de los ajolotes”, Revista de la Universidad de México, 66 (2009), 65-65.

MARTÍNEZ PÉRSICO, Marisa: “Analogías de la invención: M. C. Escher y Jorge Luis Borges”, Cartaphilus. Revista de investigación y crítica estética 7-8 (2010), 212-218.

PANIAGUA, Pablo: “QQué es la literatura fractal?”, Acequias 44 (2008), 23-26.

SARDUY, Severo (1982): La simulación. Caracas, Monte Ávila Editores Latinoamericana.

(C) Berenice Romano Hurtado

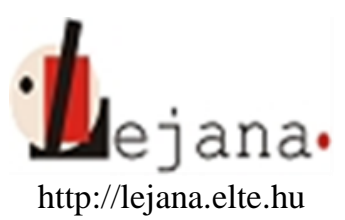

Universidad Eötvös Loránd, Departamento de Español, 1088 Budapest, Múzeum krt. 4/C

Recibido: 23 de mayo de 2016

Aceptado: 05 de agosto de 2016

Berenice Romano Hurtado: "Trazos y pinceladas: la condensación literaria como principio de construcción en «Ambystoma trigrinum» de Salvador Elizondo" 